\title{
Beyond Polaroid: Visual Rhetoric in Shaping Refugee's Identity
}

\section{Donna John}

Assistant Professor on Contract

Morning Star Home Science College

Anagamaly, Kerala, India

donnajohn1008@gmail.com

Abstract

Photographs tend to have an ability to influence the collective consciousness of humanity. Sonja K. Foss, a rhetorical educator, opines that language is general while images are concrete and specific. Many a time, photographs have become spokespersons of the suffering and needy lot. Throughout its history, photography has created opinions, constructed realities of people and brought human tragedies to the forefront. The refugee crisis is in no way an exception. In fact, the conscience of the whole world in regard to the refugees was awakened by an appalling photograph of a three-year-old Syrian toddler, Aylan Kurdi, lying face-down into the sand. Such photographs, often symbolic and termed as visual rhetoric, slowly turned into stereotypes defining the refugee crisis. This paper discusses on how these visual narratives have shaped the identity of refugees and created various regimes of seeing.

Keywords: Visual Rhetoric, Refugee Crisis, Symbolic Images, Identity. Introduction

A photograph is worth a thousand words and is believed to have the ability to influence the collective unconsciousness of humanity. Sonja K. Foss, a rhetorical educator, is of the opinion that language is general and abstract while images are concrete and specific (141). Nobody doubts that the visual has become an influential mode of perception. However, for each individual that views a photograph, those thousand words would be irreversibly 
thought and expressed in a distinctive way. In other words, image may be regarded as universal language, but they still incite interpretation; they still need to be read.

Described as a "strange, confined space" (Price 48), the photograph and the description (caption, title, text) that sometimes go with it have greatly influenced our understanding of the world. In many historical studies photographs are included to support the written text. Such photographs allow the reader to relate mental images generated by texts with visual ones. Usually, these photographs are seen as illustrations, clearly subordinate to the text. They contain a wealth of information on various socio-political relations, on aesthetic conventions, on audiences etc. They give a direct access to the past, providing credibility to the written information. Photographs, although constricted to a given space, opens the viewers eyes to see the magnified truth and empathise with it.

Human international migration movements are not a new phenomenon. They have been occurring for centuries and can be said as a constant situation in certain parts of the world. It has huge impact on social cohesiveness and over the past one hundred years, international migration has often been at the centre stage of major events that reshaped the world. Today there are around 59.5 million displaced people in the world, which includes refugees, migrants, asylum seekers and internally displaced persons. Most of the refugee stem from Syrian Arab Republic, Afghanistan, Iraq and Pakistan (UNHCR). With the cause of Syrian civil war in 2011, the refugee crisis has taken an unprecedented turn.

The central role in perceiving these tragic circumstances is held by the media. The media gave considerable insights to human tragedies in unforeseen ways, explicitly presenting desperate conditions and deaths. Public interest in refugees dramatically escalated after the image of drowned toddler Aylan Kurdi got published. It sparked the debate about thecrisis immensely. It has gained the title of an iconic photograph representing the Syrian refugee crisis and demonstrates the power of single visual image which strongly evokes 
viewer's reactions. The media's attention and focus on these events are responsible for bringing viewers images of the on-going humanitarian problems. The visual media created several such visual rhetoric and symbolic images which slowly turned to become stereotypes defining the refugee crisis.

The power of the visual imagery and visual rhetoric has received little attention in research on the representation of migration. Photographic portrayals of refugees are extremely abundant and in turn they play essential role in forming the stereotype of the refugee. As refugees are universalized visually in the media and other public fields, theses media representation determine how we see refugees and at times result with objectifying the refugee as an“illegal alien” (Wright 64).

Europe's refugee crisis was one of the most heavily mediated world events of the past decade.Scenes of desperation, suffering and rescue in various parts of the world were made available by reporters, news crews, filmmakers and artists. Many images gained the status of universal acceptance for a variety of reasons - political, commercial, but also aesthetic, like that of Aylan Kurdi lying in the hands of a police officer, which resembled Michelangelo's Pietà, an iconography of suffering and sacrifice that runs deep in European culture.

Human stories have the greatest currency among journalists and the refugee crisis emerged as a prominent one. A sea of images had swarmed the newspapers and the internet, creating a wide variety of meanings. The catch words and phrases of the period underwent considerable change according to the changing currents in media portrayals. The inherent politics and ideologies that these images and news materials carried were hidden from the public eye, which viewed the photographs as a step closer to reality. The effect, too often, was to frame these people as others; people from "over there" (The Guardian 2), who were strangers to its traditions and culture. A sympathetic portrayal of the displaced might focus on some of those images of innocence and vulnerability: children, women, families; the 
vulnerable, the sick, and the elderly while the negative coverage might focus more on the men, the able-bodied, nameless and sometimes faceless people massed at fences or gates or people from particular countries would be focused on to suit a political agenda. The problem was made worse by those media outlets that have an active desire to stoke hostility and misunderstanding.

Now, several years on from the peak of the refugee crisis, we are faced with a series of uncomfortable facts. The altered truths are slowing seeing light and the people have come face to face with the shrewd politics that worked behind the curtains, a dangerous narrative threatened to push out all the sympathy to others: that European culture and identity are threatened by intrusions from outside. If we come to view culture in this way - as something fixed and tightly bounded by the ideologies of race and religion, or as a means for wealthy parts of the world to defend their privilege - then we are headed for further, greater disasters. The irony is that we can only believe in this vision if we ignore not only history, but its present too. Movement, exchange, new connections, the making and remaking of tradition these things are happening all around us, and already involve people who have been drawn here from other parts of the world by ties not just of conflict but of economics, history, language and technology.

All too often, the voices of refugees are reduced to the photographs, which are often interpreted and contextualised on their behalf. Photographs do not make sense themselves. They need to be seen and interpreted. They gain meaning in relation to the personal and societal assumptions and norms that surround us. There are inevitable power relationships involved in this nexus between visuality, society and politics. Photographs offer a good illustration of the refugee crisis. They appear to communicate clearly and truthfully, yet deceive us. They seem to give us a glimpse of the real and provide us with the seductive belief that what we see in a photograph is an authentic representation of the event: a slice of 
life that reveals exactly what was happening at a particular moment. It is this illusion of authenticity that makes photographs such powerful tools to convey the meaning of refugee narrative to distant audiences.

The figure of the refugee is of particular political importance because it calls the world as a community of nation-states into question. Arendt highlights how the notion of the rights of man first elaborated in the French declaration of 1898 was intended to provide each human being with inalienable rights, but quickly this notion was subsumed under the idea that the rights of man would be guaranteed by the right of the people to sovereign selfgovernment in the nation- state (369). It is only for citizens of the nation-state that rights can be enacted. The result is that those who are stateless (i.e., not protected by citizenship) do not have the right to have rights, and the abstract nakedness of being nothing but human is a dangerous situation to be in. Agamben notes that refugees are granted biological survival through humanitarian efforts, but not political survival; the refugee brings to light the nation's hidden violence of inclusion or exclusion of bare life within politicised life (30).

The frames that are used for describing refugees are pallet of polarized constructions referring to them as innocent victims or stealth terrorists. If we start from the assumption that most of people's knowledge and beliefs about the world are shaped primarily by the plethora of news reports that they consume every day, we can agree that the media have significant role in framing the imagery of the refugees. Media portrayals influence how we think about identities in terms of gender, race, ethnicity and nationality.

Another important problem that arises considering media representations is the tendency to report about refugees without sensibility. Portrayed as 'enemies at the gates' who are attempting to invade western nations, the media create a crisis mentality and promote dehumanization of refugees. These kinds of portrayals include depictions which suggest that refugees spread infectious diseases, that refugee claimants are often bogus, and that terrorists 
may gain entry to western nations disguised as refugees. Media coverage often refers to cultural differences and law-breaking, refugees are frequently represented as engaging in illegal activities.

\section{Conclusion}

Migratory movements are almost always observed through the media eye. Based on the given representations, the public is witnessing the struggles of refugees and migrants. Photojournalism is often characterized as an agent for change. It has significant role in shaping the reality of the photographed subjects while presenting their surroundings and occurring conditions. Images are part of, as du Gay (1977) states, "the circuit of culture". 


\section{Works Cited}

Agamben, Giorgio. Homo Sacer: Sovereign Power and Bare Life. Translated by Daniel Heller-Roazen, Stanford University Press, 1998.

Arendt, Hannah. The Human Condition. The University of Chicago Press, 1958.

Champ, Joseph \& Brooks, Jeffrey. "The Circuit of Culture: A Strategy for Understanding the Evolving Human Dimensions of Wildland Fire. Society and Natural Resources.” Research Gate, June 2010, https://www.researchgate.net/publication/233349304_The_Circuit_of_Culture_A_Str ategy_for_Understanding_the_Evolving_Human_Dimensions_of_Wildland_Fire. Accessed 19 Apr. 2021.

Foss, Sonja K. "Theory of Visual Rhetoric.” Handbook of Visual Communication: Theory, Methods and Media. Lawrence Erlbaum Associates, 2005, pp. 141-152.

Mannik, Lynda. Photography, Memory, and Refugee Identity: The Voyage of the SS Walnut1948. UBC Press, 2013, pp. 273.

Price, Mary. The Photograph: A Strange Confined Space. Stanford University Press, 1994.

Reuters. "Shocking images of drowned boy show tragic plight of the refugees." The Guardian, 02 Sept. 2015, www.theguardian.com/world/2015/sep/02/shockingimageof-drowned-syrian-boy-shows-tragic-plight-of-refugees. Accessed 19 Apr. 2021.

Wright, Terence. "Moving images: the media representation of refugees." Visual Studies, vol.17, no. 1, 2002, pp. 53-66.

Hkarner," How the media contributed to the migrant crisis" Föhrenbergkreis Finanzwirtschaft published 5 Aug 2019 https://fbkfinanzwirtschaft.wordpress.com/2019/08/05/howthe-media-contributed-to-the-migrant-crisis/ Accessed 15 January 2021 
Bleiker Roland," Visual Global Politics" Research gate march 2018 www.researchgate.net/publication/328381146_Visual_Global_Politics Accessed date 20 February 2018 